\title{
Canadian prediction equations of spirometric lung function for Caucasian adults 20 to 90 years of age: Results from the Canadian Obstructive Lung Disease (COLD) study and the Lung Health Canadian Environment (LHCE) study
}

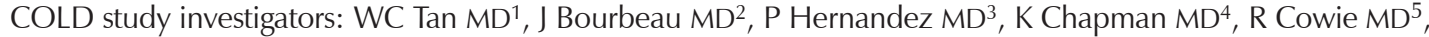 \\ MJ FitzGerald $M D^{6}$, S Aaron $M D^{7}$, DD Marciniuk $M D^{8}$, F Maltais $M D^{9}$, DE O'Donnell $M D^{10}$, R Goldstein MD ${ }^{11}$, D Sin $M D^{1}$; \\ LHCE study investigators: M Chan-Yeung $M D^{6}$, J Manfreda $\mathrm{PhD}^{12}$, NR Anthonisen $M D^{12}$, RBTate $M D^{12}, M R$ Sears $M D^{13}$, \\ HC Siersted MD ${ }^{13}$, MR Becklake MD², P Ernst MD², DM Bowie MD ${ }^{3}$, L Sweet MD ${ }^{14}$, L Van Til PhD ${ }^{14}$
}

\begin{abstract}
WC Tan, J Bourbeau, P Hernandez, et al; for the COLD study investigators; and for the LCHE study investigators. Canadian prediction equations of spirometric lung function for Caucasian adults 20 to 90 years of age: Results from the Canadian Obstructive Lung Disease (COLD) study and the Lung Health Canadian Environment (LHCE) study. Can Respir J 2011;18(6):321-326.
\end{abstract}

BACKGROUND: Currently, no reference or normative values for spirometry based on a randomly selected Canadian population exist. OBJECTIVE: The aim of the present analysis was to construct spirometric reference values for Canadian adults 20 to 90 years of age by combining data collected from healthy lifelong nonsmokers in two population-based studies. METHOD: Both studies similarly used random population sampling, conducted using validated epidemiological protocols in the Canadian Obstructive Lung Disease study, and the Lung Health Canadian Environment study. Spirometric lung function data were available from 3042 subjects in the COLD study, which was completed in 2009, and from 2571 subjects in the LHCE study completed in 1995. A total of 844 subjects 40 to 90 years of age, and 812 subjects 20 to 44 years of age, were identified as healthy, asymptomatic, lifelong nonsmokers, and provided normative reference values for spirometry. Multiple regression models were constructed separately for Caucasian men and women for the following spirometric parameters: forced expiratory volume in $1 \mathrm{~s}\left(\mathrm{FEV}_{1}\right)$, forced vital capacity (FVC) and $\mathrm{FEV}_{1} / \mathrm{FVC}$ ratio, with covariates of height, sex and age. Comparison with published regression equations showed that the best agreement was obtained from data derived from random populations.

RESULTS: The best-fitting regression models for healthy, never-smoking, asymptomatic European-Canadian men and women 20 to 90 years of age were constructed. When age- and height-corrected $\mathrm{FEV}_{1}, \mathrm{FVC}$ and $\mathrm{FEV}_{1} / \mathrm{FVC}$ ratio were compared with other spirometry reference studies, mean values were similar, with the closest being derived from populationbased studies.

CONCLUSION: These spirometry reference equations, derived from randomly selected population-based cohorts with stringently monitored lung function measurements, provide data currently lacking in Canada.

Key Words: Canadian; Prediction equations; Reference values; Spirometry
Les équations prévisionnelles canadiennes de la fonction pulmonaire spirométrique des adultes de race blanche de 20 à 90 ans : les résultats de l'étude COLD sur la maladie pulmonaire obstructive au Canada et de l'étude LHCE sur la santé pulmonaire dans les milieux canadiens

HISTORIQUE : Il n'existe pas de référence ou de valeur normative de la spirométrie selon une population canadienne sélectionnée au hasard.

OBJECTIF : La présente analyse visait à établir des valeurs de référence spirométriques pour les adultes canadiens de 20 à 90 ans en combinant des données colligées auprès de personnes qui n'avaient jamais fumé tirées de deux études en population.

MÉTHODOLOGIE : De façon similaire, les deux études faisaient appel à un échantillon aléatoire en population et avaient été menées au moyen de protocoles épidémiologiques validés dans l'étude COLD sur la maladie pulmonaire obstructive au Canada et dans l'étude LHCE sur la santé pulmonaire dans les milieux canadiens. L'étude COLD, terminée en 2009, possédait les données de fonction pulmonaire spirométrique de 3042 sujets, et l'étude LHCE, terminée en 1995, les données de 2571 sujets. Au total, 844 sujets de 40 à 90 ans et 812 sujets de 20 à 44 ans étaient considérés comme des personnes asymptomatiques en santé qui n'avaient jamais fumé et ont fourni les valeurs de référence normatives de la saturométrie. Les chercheurs ont créé des modèles de régression multiple distincts pour les hommes et les femmes de race blanche à l'égard des paramètres de spirométrie suivants : volume expiratoire maximal par seconde (VEMS), capacité vitale forcée (CVF) et rapport VEMS/CVF, incluant les covariables de la taille, du sexe et de l'âge. La comparaison avec les équations de régression publiées a démontré que le meilleur appariement provenait de données tirées de populations aléatoires.

RÉSULTATS : Les meilleurs modèles de régression ont été créés à partir d'hommes et de femmes euro-canadiens asymptomatiques en santé de 20 à 90 ans qui n'avaient jamais fumé. Lorsque la VEMS, la CVT et le rapport VEMS/CVF corrigés selon l'âge et la taille étaient comparés avec d'autres études de référence de la spirométrie, les valeurs moyennes étaient similaires, les plus près étant dérivées d'études en population.

CONCLUSION : Ces équations de référence de la spirométrie, dérivées de cohortes en population sélectionnées de manière aléatoire, dont les mesures de la fonction pulmonaire avaient été rigoureusement surveillées, fournissent des données encore inexistantes au Canada.

${ }^{1}$ UBC James Hogg Research Centre, Providence Heart + Lung Institute, St Paul's Hospital, University of British Columbia, Vancouver, British Columbia; ${ }^{2}$ Respiratory Epidemiology and Clinical Research Unit, Montreal Chest Institute, McGill University, Montreal, Quebec;

${ }^{3}$ Department of Medicine, QEII Health Sciences Centre, Dalhousie University, Halifax, Nova Scotia; ${ }^{4}$ Division of Respiratory Medicine,

Toronto Western Hospital, University of Toronto, Toronto, Ontario; ${ }^{5}$ Departments of Medicine and Community Health Sciences, University of Calgary, Calgary, Alberta; ${ }^{6}$ Division of Respiratory Medicine, University of British Columbia, Vancouver General Hospital, Vancouver, British Columbia; ${ }^{7}$ Ottawa Hospital Research Institute, University of Ottawa, Ottawa, Ontario; ${ }^{8}$ University of Saskatchewan, Royal University Hospital, Saskatoon, Saskatchewan; ${ }^{9}$ Centre de Pneumologie, Institute Universitaire de Cardiologie et de Paneumologie de Quebec, Quebec City, Quebec; ${ }^{10}$ Division of Respiratory $\mathcal{E}^{2}$ Critical Care Medicine, Queen's University, Kingston; ${ }^{11}$ Physical Therapy-Respiratory Division, University of Toronto, Ontario; ${ }^{12}$ Departments of Medicine and Community Health Sciences, University of Manitoba, Winnipeg, Manitoba;

${ }^{13}$ Firestone Institute for Respiratory Health, St Joseph's Healthcare and McMaster University, Hamilton, Ontario; ${ }^{14}$ Department of Health and Social Services, Charlottetown, Prince Edward Island

Correspondence: Dr WC Tan, UBC James Hogg Research Centre, Providence Heart + Lung Institute, University of British Columbia, St Paul's

Hospital, Rm 166, 1081 Burrard Street, Vancouver, British Columbia V6Z 1Y6. Telephone 604-806-8346, fax 604-806-8351,

e-mailwan.tan@hli.ubc.ca 
$S^{\mathrm{p}}$ irometry is the most common pulmonary function test used in the objective assessment of patients with respiratory symptoms in clinical practice because it is readily accessible, relatively easy to perform and reliable under conditions of strict quality control $(1,2)$.

Correct interpretation of spirometry in clinical practice requires comparison with previously published reference values (3). The American Thoracic Society (ATS) criteria for constructing reference values recommended that they be based on a large sample of representative populations, the use of internationally accepted equipment and methods, and appropriate statistical analysis (4). Ideally, normative values should be derived from healthy individuals identified in population-based surveys such as in the The National Health and Nutrition Examination Survey (NHANES) Study (5). However, population surveys with standardized and quality-assured lung function testing remains uncommon (5-8). In Canada, a recent publication (9) reported values for Caucasian Canadians 20 to 80 years of age that were based on lung function tests in 637 healthy nonsmokers selected from relatives and friends of patients and employees of the six participating sites. To date, no population-based spirometry reference values for Canada have been published. The availability of data from two large population-based studies - the Lung Health and Canadian Environment (LHCE) study $(10,11)$, and the Canadian Obstructive Lung Disease (COLD) study - based on the Burden of Obstructive Lung Disease (BOLD) protocol $(12-14)$ provided the opportunity to generate reference values for spirometry from randomly selected populations 20 to 90 years of age from across Canada.

The aim of the present analysis was to construct spirometric reference values for Canada in adults 20 to 90 years of age with no history of respiratory disease, by combining data from healthy, lifelong nonsmokers based on these two population-based studies, and to test how the prediction equations for spirometric measurements compare with other published American equations (5,9,15-18).

\section{METHODS}

\section{Patients}

LHCE study: The details of the LCHE study are fully described in previous publications $(10,11)$. Briefly, 18,616 individuals randomly selected from the community from six sites across Canada, answered the European Community Respiratory Health Survey (ECRHS) questionnaire. Preselected random subsamples were invited to undergo lung function testing in a research laboratory. Spirometry was performed using a dry rolling-seal spirometer (Grasbe-Andersen, Spirotech Division, USA) using the Lung Health study protocol and computer software (19). The study was conducted between March 1993 and November 1994.

COLD study: Details regarding the subjects and methodology in the COLD study have been described in previous publications $(12,14,20,21)$. This epidemiological study to determine the prevalence of chronic obstructive pulmonary disease (COPD) was a nationwide, cross-sectional, multisite and population-based analysis that used spirometry as the main diagnostic tool. It was initiated in Vancouver (British Columbia) in August 2005, and completed at five sites (Vancouver, Montreal [Quebec], Toronto [Ontario], Halifax [Nova Scotia] and Calgary [Alberta]) by May 2009. Briefly, the strategy and instruments were the same as those used in the international BOLD initiative $(12,14,20,21)$. Trained and certified technicians conducted interviews using the BOLD questionnaires, which contained information on respiratory symptoms and diseases, smoking history and other risk factors for COPD, medication use, health care use, activity limitation and health-related quality of life. Lung function data were obtained with the use of the ndd EasyOne spirometer (ndd Medical Technologies, USA), in which spirometry was performed before and 15 min after administration of $200 \mu \mathrm{g}$ of salbutamol/albuterol (12-14,20). Strict quality assurance of spirograms involve scoring of all tracings based on acceptability and reproducibility criteria of the ATS and European Respiratory Society (ERS) $(1,22)$. The present analysis used data acquired from 3042 individuals who were 40 years of age or older, and identified healthy, never-smokers with no respiratory disease.

\section{Inclusion criteria for reference values}

To generate reference values, prebronchodilator spirometric values were used. Subjects were selected using questionnaire and anthropometric data. The exclusion and inclusion criteria were similar to those described in the study by Hankinson et al (5). Healthy subjects were never-smokers without a respiratory diagnosis of current asthma (present in the preceding 12 months), current chronic bronchitis, emphysema, COPD, tuberculosis, no hospitalization for respiratory illness in childhood, and no chronic symptoms of cough, sputum or wheeze. In addition, subjects were required to have three acceptable spirometric tracings of forced expiratory volume in $1 \mathrm{~s}\left(\mathrm{FEV}_{1}\right)$ and forced vital capacity (FVC), with a variation of $<200 \mathrm{~mL}$ between the two greatest values (1). The exclusion criteria for the two cohorts are shown in Tables 1 and 2.

\section{Statistical analysis}

Statistical analyses were performed using SAS version 9.1.3 (SAS Institute, USA). Reference equations and equations to calculate the 5 th percentile lower limit of normal (LLN) criteria were developed during the SAS procedures PROC REG and PROG UNIVARIATE. Each of the spirometry measures was entered into a multiple regression model using age, height $(\mathrm{cm})$ and sex as predictors. Nonlinear relationships were also tested by including the square of age, height, their interactions, weight and body mass index (BMI) in the regression equations. Predictor variables were retained in the regression model only if their addition significantly improved $\mathrm{R}^{2}$, and the SE of the differences decreased. Men and women were analyzed separately. For each spirometric variable, in addition to the mean value, the SE of the estimate (SEE or SD of the residuals) was determined to enable the computation of the LLN, which is estimated using the following equation:

$$
\text { LLN }=\text { Predicted value }-(1.645 \times \mathrm{SEE})
$$

The spirometric values generated by the study were also compared with those of seven previous spirometry reference studies: two populationbased studies with randomly sampled populations, namely the North American population in the NHANES study by Hankinson et al (5), and the South American population in the Chronic Obstructive Pulmonary Disease in Five Latin American Cities (PLATINO) study (18); one Canadian study that used a selected convenience sample of subjects (Gutierrez et al [9]); and four studies that are approximately 18 to 40 years old, which generated reference values that are still widely used in Canada (2,15-17).

\section{RESULTS}

A total of 812 participants ( 20 to 44 years of age) from the total sample of 2892 participants (28\%) in the LHCE study, and 844 (40 to 90 years of age) from the total sample of 3042 participants (28\%) in the COLD study were identified as healthy, asymptomatic, lifelong Caucasian nonsmokers in Canada, and provided normative reference values for spirometry. These individuals had never smoked, had not been diagnosed with respiratory diseases and did not exhibit respiratory symptoms. The method of selection from the two study cohorts are shown in Tables 1 and 2. Table 3 summarizes the general characteristics of the subjects in the two studies.

All healthy subjects included in each study met the quality criteria proposed by the ATS and ERS (three acceptable manoeuvres and repeatability defined as readings between the two best values for $\mathrm{FEV}_{1}$ and FVC $<200 \mathrm{~mL}$ ) (4).

Figure 1 presents scatterplots of $\mathrm{FEV}_{1}$ and of FVC for men and women from the LHCE study (20 to 44 years of age) and the COLD study (40 to 90 years of age). The figures demonstrate the continuity of the $\mathrm{FEV}_{1}$ and $\mathrm{FVC}$ values for the different age ranges examined in the two studies, and overlapping values for the ages of 40 to 44 years from the two cohorts. 
TABLE 1

Exclusion criteria for the selection of healthy, nonsmoker Caucasians in the Lung Health and Canadian Environment study (age range 20 to 44 years)

\begin{tabular}{|c|c|c|c|c|c|c|}
\hline \multirow[b]{2}{*}{ Criteria } & \multicolumn{2}{|c|}{ Men $(n=1163)$} & \multicolumn{2}{|c|}{ Women $(n=1408)$} & \multicolumn{2}{|c|}{ Total $(n=2571)$} \\
\hline & Excluded & Remaining & Excluded & Remaining & Excluded & Remaining \\
\hline $\mathrm{FEV}_{1}$ or FVC data missing & 33 & 1130 & 65 & 1343 & 98 & 2473 \\
\hline Smoker or exsmoker & 576 & 558 & 689 & 654 & 1261 & 1212 \\
\hline History of asthma & 60 & 498 & 88 & 566 & 148 & 1064 \\
\hline Lung problem before 16 years of age & 33 & 465 & 47 & 519 & 80 & 984 \\
\hline Cough for $>3$ months & 21 & 444 & 42 & 477 & 63 & 921 \\
\hline Sputum production for $>3$ months & 12 & 432 & 13 & 464 & 25 & 896 \\
\hline Wheeze apart from colds & 26 & 406 & 30 & 434 & 56 & 840 \\
\hline Woken by shortness of breath & 11 & 395 & 17 & 417 & 28 & 812 \\
\hline
\end{tabular}

Data presented as $n$. FEV 1 Forced expiratory volume in $1 \mathrm{~s}$; FVC Forced vital capacity

TABLE 2

Exclusion criteria for the selection of healthy, nonsmoker Caucasian subjects in the Canadian Obstructive Lung Disease study (age range 40 to 90 years)

\begin{tabular}{|c|c|c|c|c|c|c|}
\hline \multirow[b]{2}{*}{ Criteria } & \multicolumn{2}{|c|}{ Men $(n=1234)$} & \multicolumn{2}{|c|}{ Women $(n=1808)$} & \multicolumn{2}{|c|}{ Total $(n=3042)$} \\
\hline & Excluded & Remaining & Excluded & Remaining & Excluded & Remaining \\
\hline Smoker or exsmoker & 706 & 528 & 893 & 915 & 1599 & 1443 \\
\hline MD diagnosis of emphysema & 2 & 526 & 6 & 909 & 8 & 1435 \\
\hline MD diagnosis of current asthma & 43 & 483 & 107 & 802 & 150 & 1285 \\
\hline MD diagnosis of COPD & 2 & 481 & 5 & 797 & 7 & 1278 \\
\hline MD diagnosis of tuberculosis & 6 & 475 & 16 & 781 & 22 & 1256 \\
\hline $\begin{array}{l}\text { MD diagnosis of current chronic bron- } \\
\text { chitis }\end{array}$ & 2 & 473 & 6 & 775 & 8 & 1248 \\
\hline Non-Caucasian & 67 & 406 & 151 & 624 & 218 & 1030 \\
\hline Unacceptable spirometry data & 17 & 389 & 15 & 609 & 32 & 998 \\
\hline $\begin{array}{l}\text { Hospitalized for breathing problems } \\
\text { before } 10 \text { years of age }\end{array}$ & 18 & 371 & 24 & 585 & 42 & 956 \\
\hline Cough for $>3$ months & 22 & 349 & 39 & 546 & 61 & 895 \\
\hline Sputum for $>3$ months & 7 & 342 & 16 & 530 & 23 & 872 \\
\hline Wheeze apart from colds & 8 & 334 & 20 & 510 & 28 & 844 \\
\hline
\end{tabular}

Data presented as n. COPD Chronic obstructive pulmonary disease; MD Physician

TABLE 3

Baseline characteristics and spirometric measurements for the healthy, nonsmoker Caucasian subjects in the Lung Health Canadian Environment (LHCE) and Canadian Obstructive Lung Disease (COLD) study populations

\begin{tabular}{|c|c|c|c|c|}
\hline \multirow[b]{2}{*}{ Variable } & \multicolumn{2}{|c|}{ LHCE } & \multicolumn{2}{|c|}{ COLD } \\
\hline & Women $(n=417)$ & Men $(n=395)$ & Women $(n=510)$ & Men $(n=334)$ \\
\hline Age, years & $31.5 \pm 6.9$ & $31.4 \pm 6.9$ & $56.5 \pm 10.9$ & $54.8 \pm 10.3$ \\
\hline Height, cm & $164.2 \pm 6.8$ & $176.8 \pm 6.4$ & $162.4 \pm 6.7$ & $176.1 \pm 7.3$ \\
\hline Weight, kg & $66.1 \pm 13.7$ & $81.6 \pm 13.4$ & $71.2 \pm 16.4$ & $85.8 \pm 16.1$ \\
\hline Body mass index, $\mathrm{kg} / \mathrm{m}^{2}$ & $24.5 \pm 4.9$ & $26.1 \pm 4.0$ & $27.0 \pm 6.2$ & $27.6 \pm 4.6$ \\
\hline $\mathrm{FEV}_{1}, \mathrm{~L}$ & $3.30 \pm 0.48$ & $4.40 \pm 0.62$ & $2.51 \pm 0.56$ & $3.60 \pm 0.68$ \\
\hline FVC, L & $3.92 \pm 0.58$ & $5.37 \pm 0.77$ & $3.32 \pm 0.71$ & $4.82 \pm 0.87$ \\
\hline $\mathrm{FEV}_{6}, \mathrm{~L}$ & * & * & $3.19 \pm 0.68$ & $4.58 \pm 0.82$ \\
\hline $\mathrm{FEV}_{1} / \mathrm{FVC}, \%$ & $84.5 \pm 6.0$ & $82.3 \pm 5.5$ & $75.7 \pm 5.8$ & $74.9 \pm 6.1$ \\
\hline $\mathrm{FEV}_{1} / \mathrm{FEV}_{6}, \%$ & * & * & $78.9 \pm 4.3$ & $78.6 \pm 4.5$ \\
\hline
\end{tabular}

Data presented as mean \pm SD. *Data not available. FEV 1 Forced expiratory volume in 1 s; FEV 6 Forced expiratory volume in 6 s; FVC Forced vital capacity

The prediction equations for men and women between 20 and 90 years of age compiled from the two study cohorts are shown in Table 4. The height-squared and age-squared terms were not significant for predicting $\mathrm{FEV}_{1}, \mathrm{FVC}$ or $\mathrm{FEV}_{1} / \mathrm{FVC}$ and, therefore, the final equations used linear terms.

Comparison of spirometry with previous studies

Table 5 summarizes the mean spirometry values for Caucasians in our combined study population, expressed as percentage of normal predicted according to previously published regression equations: four commonly used sources of spirometry prediction equations $(5,15-17)$, and with two more recently published regression equations $(9,18)$.
Values for spirometric variables from our study were approximately $8 \%$ higher than the $\mathrm{FEV}_{1}$ predicted by Morris et al (17) and for FVC reported by Knudson et al (16), and approximately $5 \%$ lower than those predicted by a previous Canadian study of a healthy convenience sample reported by Gutierrez et al (9). However, they were very similar to those predicted by the regression equations reported in three other studies: for Caucasian Americans derived from the NHANES population-based study by Hankinson et al (5); for South American subjects from another population-based study (18); and for Caucasian Americans reported by Crapo et al (15). Figures $2 \mathrm{~A}$ and $2 \mathrm{~B}$ present $\mathrm{FEV}_{1}$ values for Caucasian men and women, with increasing age at a constant height for our cohort and as predicted according to other published 


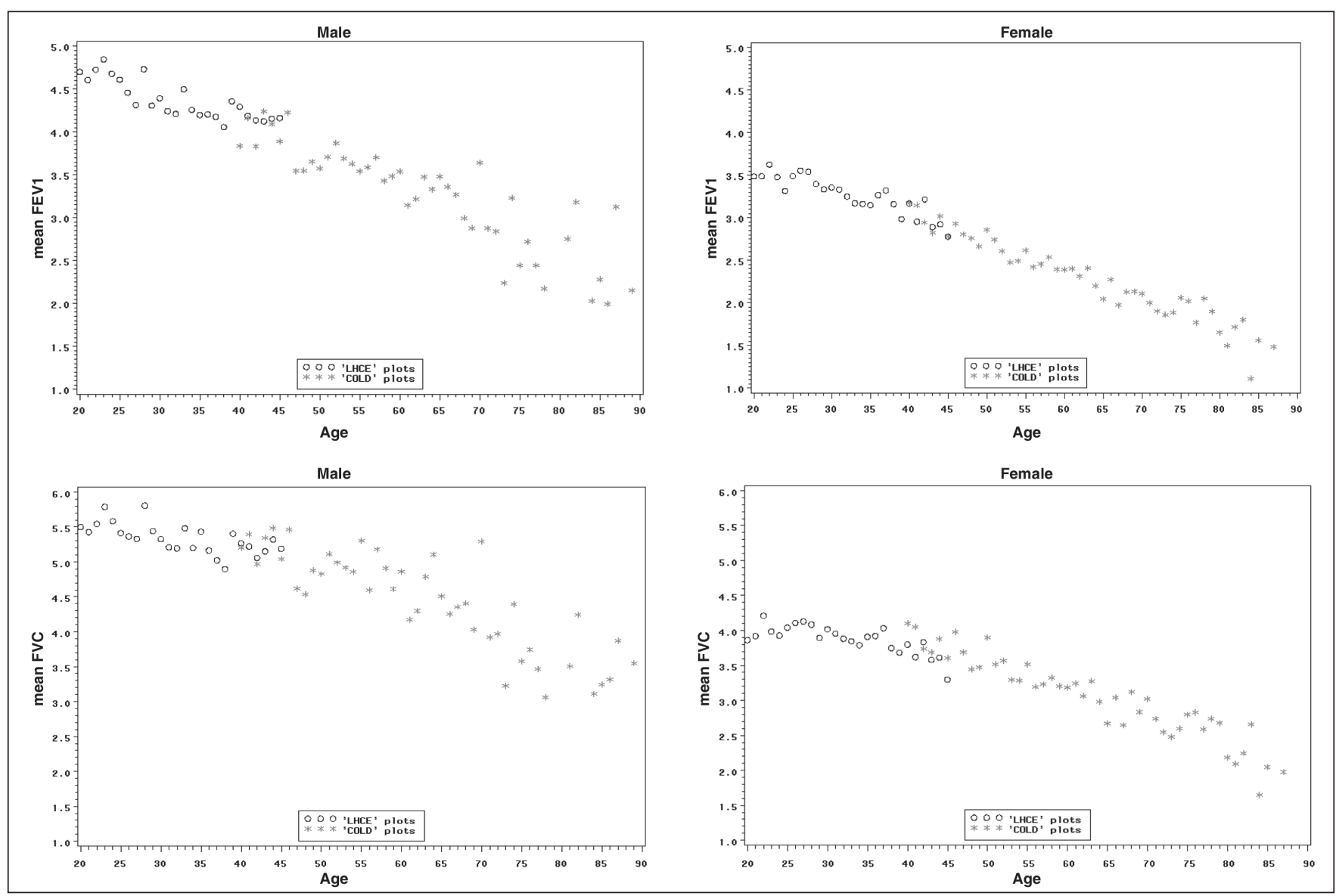

Figure 1) Scatterplots of the spirometric variables forced expiratory volume in $1 \mathrm{~s}$ (FEV1) (upper panel) and forced vital capacity (FVC) (lower panel) versus age for men (upper left and lower left) and women (upper right and lower right) from the collated data of the Lung Health and Canadian Environment (LHCE) study (20 to 44 years of age) and the Canadian Obstructive Lung Disease (COLD) study (40 to 90 years of age)

\section{TABLE 4}

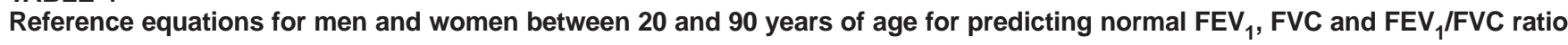
$(n=1656)$

\begin{tabular}{|c|c|c|c|c|c|c|c|}
\hline Sex & Parameter & Intercept & Age & Height & $\mathbf{R}^{2}$ & SD of difference (SEE)* & Observations, $\mathbf{n}$ \\
\hline \multirow[t]{3}{*}{ Male } & $\mathrm{FEV}_{1}$ & -2.06961 & -0.03167 & 0.04215 & 0.56010 & 0.50586 & 722 \\
\hline & FVC & -5.39383 & -0.02286 & 0.06500 & 0.45720 & 0.63557 & 708 \\
\hline & $\mathrm{FEV}_{1} / \mathrm{FVC}$ & 122.0893 & -0.27977 & -0.17794 & 0.35770 & 5.48656 & 703 \\
\hline \multirow[t]{3}{*}{ Female } & $\mathrm{FEV}_{1}$ & -1.68697 & -0.02773 & 0.03557 & 0.68390 & 0.36973 & 926 \\
\hline & FVC & -4.11886 & -0.02124 & 0.05310 & 0.52160 & 0.49381 & 917 \\
\hline & $\mathrm{FEV}_{1} / \mathrm{FVC}$ & 120.59691 & -0.30805 & -0.16531 & 0.39550 & 5.68808 & 916 \\
\hline
\end{tabular}

Men: $F_{E V}=0.04215 \times$ height $(\mathrm{cm})-0.03167 \mathrm{~A}-2.06961 ; \mathrm{FVC}=0.06500 \times$ height $(\mathrm{cm})-0.02286 \mathrm{~A}-5.39383 ; \mathrm{FEV} / \mathrm{FVC}=-0.17794 \times$ height $(\mathrm{cm})-0.27977 \mathrm{~A}+$ 122.0893; Women: FEV $1=0.03557 \times$ height $(\mathrm{cm})-0.02773 \mathrm{~A}-1.68697 ; \mathrm{FVC}=0.05310 \times$ height $(\mathrm{cm})-0.02124 \mathrm{~A}-4.11886 ; \mathrm{FEV} / \mathrm{FVC}=-0.16531 \times$ height $(\mathrm{cm})$ $-0.30805 A+120.59691$. *The 5th percentile lower limit of normal (LLN) of the population can be computed for these lung function parameters using the following formula: $L L N=$ predicted value $-(1.645 \times$ SEE). FEV 1 Forced expiratory volume in $1 \mathrm{~s}$; FVC Forced vital capacity; SEE Standard error of the estimate

regression equations. Again, the $\mathrm{FEV}_{1}$ values at different ages for Caucasian men and women of a fixed height in the present study were most similar to those predicted by the two population-based studies (ie, NHANES [5] and the PLATINO study [18]), with overestimation by the convenience sample of the Gutierrez et al (9) regression equation and underestimation by the oldest reference equations still in use (17).

\section{DISCUSSION}

We have constructed reference regression equations for spirometry based on healthy subjects derived from two population-based studies in Canada, for predicting the normative spirometric values of $\mathrm{FEV}_{1}$, FVC and $\mathrm{FEV}_{1} / \mathrm{FVC}$ ratio. For the predicted values of these variables, we included the usual mean values that are most widely used for lung function interpretation, but we also provided the SEE for the simplified determination of the 5 th percentile as the LLN, which has become increasingly accepted in recent years as an alternative measure for defining airway obstruction (23-26).

The present study, which merged two studies of continuous age ranges, has the advantage of being based on representative population samples from eight major cities/sites in Canada, and of having being conducted using validated and standardized methods in accordance with international recommendations. It represents an advance in the pre-existing values used in Canada, which were calculated from convenience samples (9).

Merging the two data sets enabled us to generate regression equations for predicting normative spirometric values for use in adults across a wide age range (20 to 90 years). We were encouraged to do so by the similarities between the two studies: the sampling method was similar, and random samples of the population were obtained using 
TABLE 5

Spirometry parameter values for Caucasians in the study
population (COLD and LHCE cohorts combined) according
to regression equations reported in other studies

\begin{tabular}{|c|c|c|}
\hline Author (reference), year & Women & Men \\
\hline \multicolumn{3}{|l|}{ Hankinson et al (5), 1999} \\
\hline $\mathrm{FEV}_{1}, \mathrm{~L}, \%$ predicted & $98.7 \pm 13.9$ & $99.4 \pm 13.0$ \\
\hline FVC, L, \% predicted & $100.4 \pm 13.7$ & $100.1 \pm 12.6$ \\
\hline $\mathrm{FEV}_{1} / \mathrm{FVC}, \%$ & $98.1 \pm 7.3$ & $99.4 \pm 7.2$ \\
\hline \multicolumn{3}{|l|}{ Perez-Padilla et al (8), 2006} \\
\hline $\mathrm{FEV}_{1}, \mathrm{~L}, \%$ predicted & $101.6 \pm 14.0$ & $101.1 \pm 13.0$ \\
\hline FVC, L, \% predicted & $100.6 \pm 13.8$ & $99.4 \pm 12.6$ \\
\hline $\mathrm{FEV}_{1} / \mathrm{FVC}, \%$ predicted & $99.7 \pm 7.4$ & $99.3 \pm 7.1$ \\
\hline \multicolumn{3}{|l|}{ Gutierrez et al (9), 2006} \\
\hline $\mathrm{FEV}_{1}, \mathrm{~L}, \%$ predicted & $95.0 \pm 13.1$ & $96.1 \pm 12.4$ \\
\hline FVC, L, \% predicted & $100.4 \pm 13.8$ & $96.6 \pm 12.2$ \\
\hline $\mathrm{FEV}_{1} / \mathrm{FVC}, \%$ predicted & $97.4 \pm 7.4$ & $97.9 \pm 7.0$ \\
\hline \multicolumn{3}{|l|}{ Morris et al (17), 1971} \\
\hline $\mathrm{FEV}_{1}, \mathrm{~L}, \%$ predicted & $108.0 \pm 15.0$ & $106.7 \pm 13.8$ \\
\hline FVC, L, \% predicted & $104.8 \pm 14.3$ & $102.5 \pm 13.0$ \\
\hline $\mathrm{FEV}_{1} / \mathrm{FVC}, \%$ predicted & $104.6 \pm 7.8$ & $104.8 \pm 7.4$ \\
\hline \multicolumn{3}{|l|}{ Crapo et al (3), 1981} \\
\hline $\mathrm{FEV}_{1}, \mathrm{~L}, \%$ predicted & $100.3 \pm 13.8$ & $98.4 \pm 12.9$ \\
\hline FVC, L, \% predicted & $104.1 \pm 14.2$ & $101.5 \pm 12.8$ \\
\hline $\mathrm{FEV}_{1} / \mathrm{FVC}, \%$ predicted & $96.9 \pm 7.0$ & $97.2 \pm 7.2$ \\
\hline \multicolumn{3}{|l|}{ Knudson et al (16), 1983} \\
\hline $\mathrm{FEV}_{1}, \mathrm{~L}, \%$ predicted & $104.3 \pm 14.7$ & $101.6 \pm 14.0$ \\
\hline FVC, L, \% predicted & $109.0 \pm 14.8$ & $106.0 \pm 14.5$ \\
\hline $\mathrm{FEV}_{1} / \mathrm{FVC}, \%$ predicted & $96.1 \pm 7.2$ & $96.0 \pm 7.5$ \\
\hline \multicolumn{3}{|l|}{ Quanjer et al (25), 1993} \\
\hline $\mathrm{FEV}_{1}, \mathrm{~L}, \%$ predicted & $105.7 \pm 14.9$ & $104.1 \pm 13.4$ \\
\hline FVC, L, \% predicted & $114.0 \pm 16.4$ & $110.3 \pm 14.3$ \\
\hline $\mathrm{FEV}_{1} / \mathrm{FVC}, \%$ predicted & $98.9 \pm 7.4$ & $99.1 \pm 7.3$ \\
\hline
\end{tabular}

Data presented as mean $\pm S D$. COLD Canadian Obstructive Lung Health

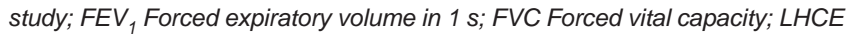
Lung Health and Canadian Environment study

either random-digit dialing or random selection from population frames $(10,20)$. The respiratory questionnaires used in the studies contained core questions that were very similar. In the LHCE study, additional questions were included to detect asthma in subjects 20 to 44 years of age, while the COLD study, using the BOLD questionnaire, used questions aimed at detecting asthma and COPD in individuals older than 40 years of age. Both studies included stringent quality control. The LHCE cohort used the spirometry quality assurance protocols of the Lung Health study (19), while the COLD study adopted the BOLD initiative protocol for quality assurance of all spirometry tracings (13). Both of these protocols defined 'a priori' participant preparation, manoeuvre acceptability and reproducibility, technician training and performance monitoring, equipment design and calibration, and result processing to minimize short-term, intra-individual $\mathrm{FEV}_{1}$ variability. The quality of the tests in the COLD study was excellent $-96 \%$ of the spirometry tracings fulfilled the ATS criteria for acceptability and reproducibility (1). Only data from tracings that satisfied these criteria were used for the generation of the regression equations.

In both the LHCE and the COLD studies, we used the ATS recommendation for healthy subject selection for normative reference values (4). The ATS criteria had defined 'healthy' as "never smokers, free of respiratory symptoms and disease". Standardized questions regarding cardiopulmonary symptoms and disease are contained in both the European Community Respiratory Health Survey questionnaires and the BOLD questionnaire sets used in the two studies. We attempted to

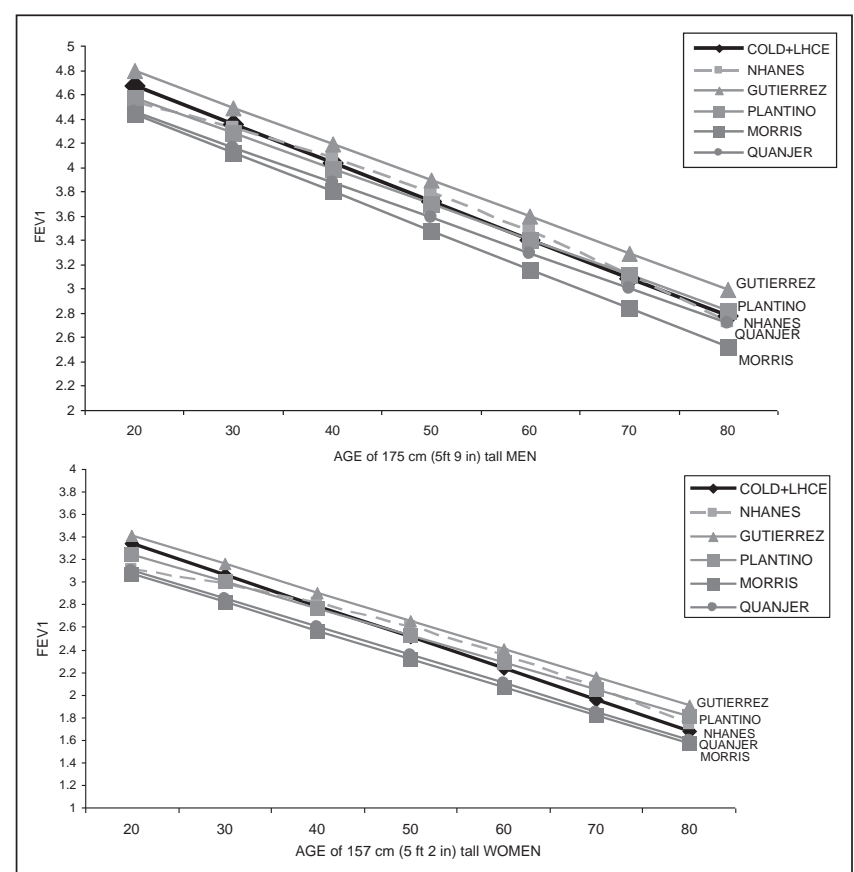

Figure 2) Predicted forced expiratory volume in $1 \mathrm{~s}$ (FEV1) values for healthy men (upper panel) and for healthy women (lower panel) from combined chorts of the COLD and LHCE studies are compared with those from other spirometry reference equations. COLD Canadian Obstructive Lung Disease study; LCHE Lung Health and Canadian Environment study; NHANES National Health and Nutrition Examination Survey

include the same list of exclusion criteria for the selection of healthy subjects from the two cohorts with small differences relevant to the two different age cohorts, such as a history of chronic bronchitis, emphysema and COPD in the older age cohort of the COLD study, and the presence of nocturnal wheezing in the younger age cohort.

A potential limitation of the present study is that the regression equations for spirometry were derived from a combined data set collated from two studies conducted 10 years apart - it is conceivable that demographic and environmental factors may have changed during the intervening time period. However, in our exploratory scrutiny of the data points, these factors did not cause real concern because the spirometric values of $\mathrm{FEV}_{1}$ and $\mathrm{FVC}$ for subjects 40 to 44 years of age from the two cohorts showed good overlap, and the values with increasing age showed excellent continuity for the entire age range from 20 to 90 years. We further investigated this by generating values for $\mathrm{FEV}_{1}$ and FVC using separate equations for the LHCE cohort and COLD cohort using standardized values for men ( $180 \mathrm{~cm}$ tall, 43 years of age) and women $\left(160 \mathrm{~cm}\right.$ tall, 43 years of age), and found that the $\mathrm{FEV}_{1}$ differed by $190 \mathrm{~mL}$ for men and $100 \mathrm{~mL}$ for women. For FVC, the difference was $14 \mathrm{~mL}$ for men and $75 \mathrm{~mL}$ for women, which were all within the range of measurement variations (2). This further justified the merging of the two data sets.

Canada contains a large population composed of many ethnic origins (5). It would be ideal to provide lung function reference values for a variety of race/ethnic groups. In the present study, however, we were only able to generate normative spirometry values for Caucasians in Canada because the number of non-Caucasian participants who met the criteria for good respiratory health was too small $(n<80)$ to attempt to generate separate equations according to age ranges. To generate population-based samples of major ethnic groups, including Asians and First Nations, would require additional resources and studies.

The predictive equations currently used in Canada were generated in the United States $(5,15-17)$. We were interested in comparing these prediction equations and a set of Canadian equations derived from selected volunteers (9) with that generated from the present study. 
The normative values generated from our regression equations were $8 \%$ higher for $\mathrm{FEV}_{1}$ and $9 \%$ higher for $\mathrm{FVC}$ compared with those from the predictive equations of Morris et al (17) and Knudson et al (16), which are still widely used in Canada even though the data are 30 to 40 years old, and were generated using Caucasian populations of the United States.

The values predicted by our population-based, Canadian spirometric reference equations did not show perfect agreement when compared with the previously published Canadian regression equation by Gutierrez et al (9). Values for spirometric variables in healthy subjects in our study were approximately $4 \%$ to $5 \%$ lower than the predicted $\mathrm{FEV}_{1}$ and $\mathrm{FVC}$ from the Gutierrez equations. A potential reason may be the difference between the healthy subjects in the two studies because healthy individuals in a convenience sample of volunteers (which was potentially biased) reported by Gutierez et al (9) may have had 'superior' lung function than those drawn from the random representative populations in our study. It is interesting to note that the normative values generated from our regression analysis agree best with those generated by two other population-based studies - the Caucasian-American regression analysis by Hankinson et al (5), and the Latin-American regression analysis from the PLATINO study (18). These differences have clinical implications in the interpretation of lung function testing because regression equations that underestimate normative values could miss abnormalities, and equations that overestimate could overdetect abnormalities.

It would be more appropriate to use regression equations that are derived from populations most representative of the subjects to be

\section{REFERENCES}

1. ATS. Standardization of Spirometry, 1994 Update. American Thoracic Society. Am J Respir Crit Care Med 1995;152:1107-36.

2. Quanjer PH, Tammeling GJ, Cotes JE, et al. Lung volumes and forced ventilatory flows. Report Working Party Standardization of Lung Function Tests, European Community for Steel and Coal. Official statement of the European Respiratory Society. Eur Respir J 1993;(Suppl):16:5-40.

3. Crapo RO. The role of reference values in interpreting lung function tests. Eur Respir J 2004;24:341-2.

4. American Thoracic Society. Lung function testing: selection of reference values and interpretative strategies. American Thoracic Society. Am Rev Respir Dis 1991;144:1202-18.

5. Hankinson JL, Odencrantz JR, Fedan KB. Spirometric reference values from a sample of the general U.S. population. Am J Respir Crit Care Med 1999;159:179-87.

6. Fukuchi Y, Nishimura M, Ichinose M, et al. COPD in Japan: The Nippon COPD Epidemiology study. Respirology 2004;9:458-65.

7. Kim DS, Kim YS, Jung KS, et al. Prevalence of chronic obstructive pulmonary disease in Korea: A population-based spirometry survey. Am J Respir Crit Care Med 2005;172:842-7.

8. Menezes AM, Perez-Padilla R, Jardim JR, et al. Chronic obstructive pulmonary disease in five Latin American cities (the PLATINO study): A prevalence study. Lancet 2005;366:1875-81.

9. Gutierrez C, Ghezzo RH, Abboud RT, et al. Reference values of pulmonary function tests for Canadian Caucasians. Can Respir J 2004;11:414-24.

10. Manfreda J, Becklake MR, Sears MR, et al. Prevalence of asthma symptoms among adults aged 20-44 years in Canada. CMAJ 2001;164:995-1001.

11. Manfreda J, Sears MR, Becklake MR, et al. Geographic and gender variability in the prevalence of bronchial responsiveness in Canada. Chest 2004;125:1657-64.

12. Buist AS, McBurnie MA, Vollmer WM, et al. International variation in the prevalence of COPD (the BOLD Study): A population-based prevalence study. Lancet. 2007;370:741-50.

13. Buist AS, Vollmer WM, Sullivan SD, et al. The Burden of Obstructive Lung Disease Initiative (BOLD): Rationale and design. COPD 2005;2:277-83. tested (4). Hence, the reference values in the current study represent an advancement for spirometry testing in Canada. Tables and nomograms of reference values are available for download from the CanCOLD website (www.cancold.ca). We propose that it is time for older equations, which were used as a default in the past, to be replaced by representative, population-based and Canadian-derived regression equations.

ACKNOWLEDGEMENTS: The authors thank the men and women who participated in the study: Aimee Jong, Shen Gao, WenWang (Vancouver), Palmina Mancino (Montreal), Patricia McClean and Heather Sporn (Toronto), Ann Cowie (Calgary), Scott Fulton, Maria Yorke, Julia Weir, and Natalie Fioratos (Halifax) for assisting in data collection; and Eddy Wang, Rita So, Jeong Min, Ying Yuan, Daniel Chen, Lu Zheng and Tina Yang for assistance in data management and statistical analyses.

FUNDING: Support for the COLD (CanCOLD) study was provided by unrestricted educational grants from AstraZeneca Canada, Boehringer-Ingelheim Canada, GlaxoSmithKline Canada, Pfizer Canada and the Canadian Institute of Health Research Rx\&D Collaborative Research Program. Support for the LHCE study was from the National Health Research and Development Programme; Glaxo Canada; and the Government of the Province of Prince Edward Island. The funding sponsors had no role in the design of the study, the collection, analysis or interpretation of the data, or the writing of the report.

14. Tan W, Sin D, Balson D, et al. The Burden of Obstructive Lung Disease (BOLD) study in Vancouver, Canada - sampling and recruitment. Can Respir J 2007;14(Suppl A):7A-9A.

15. Crapo RO, Morris AH, Gardner RM. Reference spirometric values using techniques and equipment that meet ATS recommendations. Am Rev Respir Dis 1981;123:659-64.

16. Knudson RJ, Lebowitz MD, Holberg CJ, Burrows B. Changes in the normal maximal expiratory flow-volume curve with growth and aging. Am Rev Respir Dis 1983;127:725-34.

17. Morris JF, Koski A, Johnson LC. Spirometric standards for healthy nonsmoking adults. Am Rev Respir Dis 1971;103:57-67.

18. Perez-Padilla R, Valdivia G, Muino A, et al. [Spirometric reference values in 5 large Latin American cities for subjects aged 40 years or over.] Arch Bronchoneumol 2006;42:317-25.

19. Enright PL, Johnson LR, Connett JE, Voelker H, Buist AS. Spirometry in the Lung Health Study. 1. Methods and quality control. Am Rev Respir Dis 1991;143:1215-23.

20. Tan WC, FitzGerald JM, Cowie R, et al. Can age and gender explain the variation in COPD rates across large urban cities? A population-study in Canada. Int J Tubercul Lung Dis 2011 (In Press).

21. Tan WC, Lo C, Jong A, et al. Marijuana and chronic obstructive lung disease: A population-based study. CMAJ 2009;180:814-20.

22. Miller MR, Hankinson J, Brusasco V, et al. Standardisation of spirometry. Eur Respir J 2005;26:319-38.

23. Miller MR, Quanjer PH, Swanney MP, Ruppel G, Enright PL. Interpreting lung function data using $80 \%$ predicted and fixed thresholds misclassifies more than $20 \%$ of patients. Chest 2011;139:52-9.

24. Pellegrino R, Viegi G, Brusasco V, et al. Interpretative strategies for lung function tests. Eur Respir J 2005;26:948-68.

25. Quanjer PH, Enright PL, Miller MR, et al. The need to change the method for defining mild airway obstruction. Eur Respir J 2011;37:720-2.

26. Vollmer WM, Gislason T, Burney P, et al. Comparison of spirometry criteria for the diagnosis of COPD: Results from the BOLD study. Eur Respir J 2009;34:588-97. 


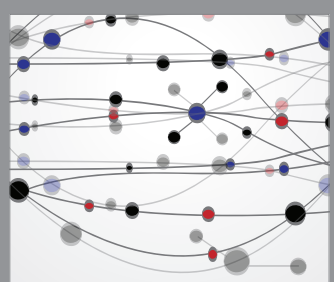

The Scientific World Journal
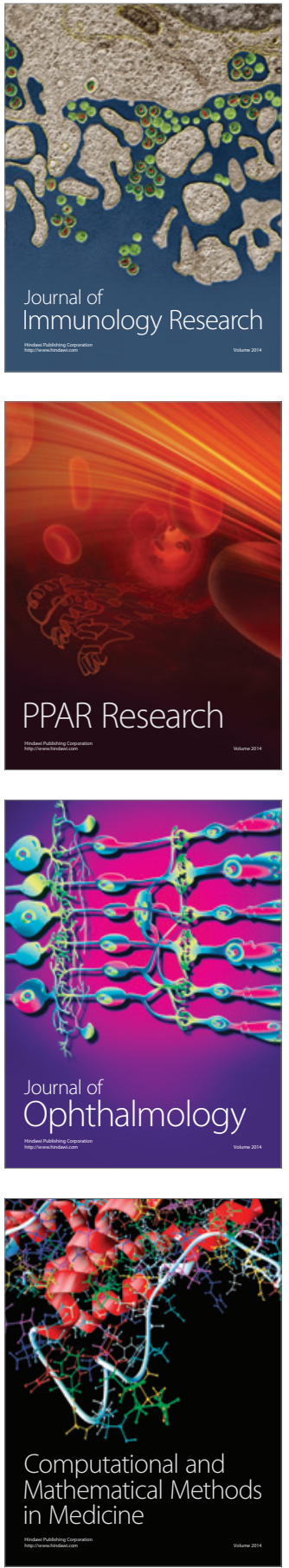

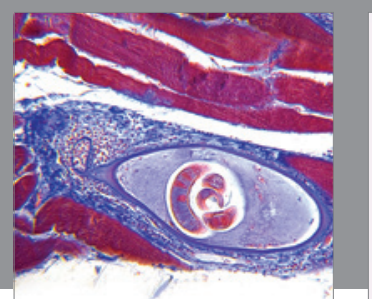

Gastroenterology Research and Practice

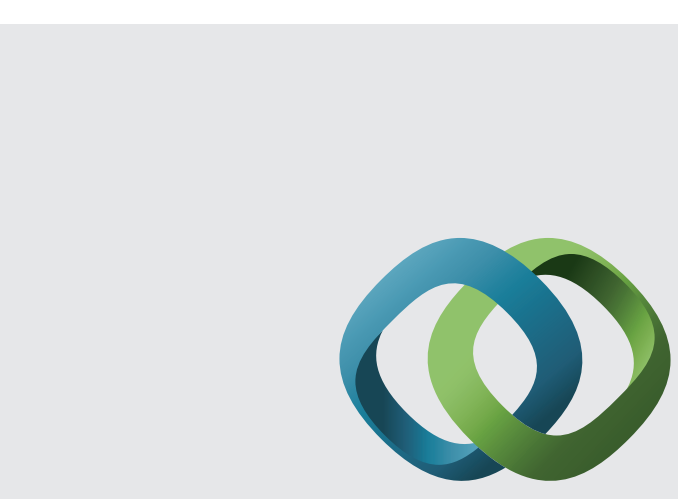

\section{Hindawi}

Submit your manuscripts at

http://www.hindawi.com
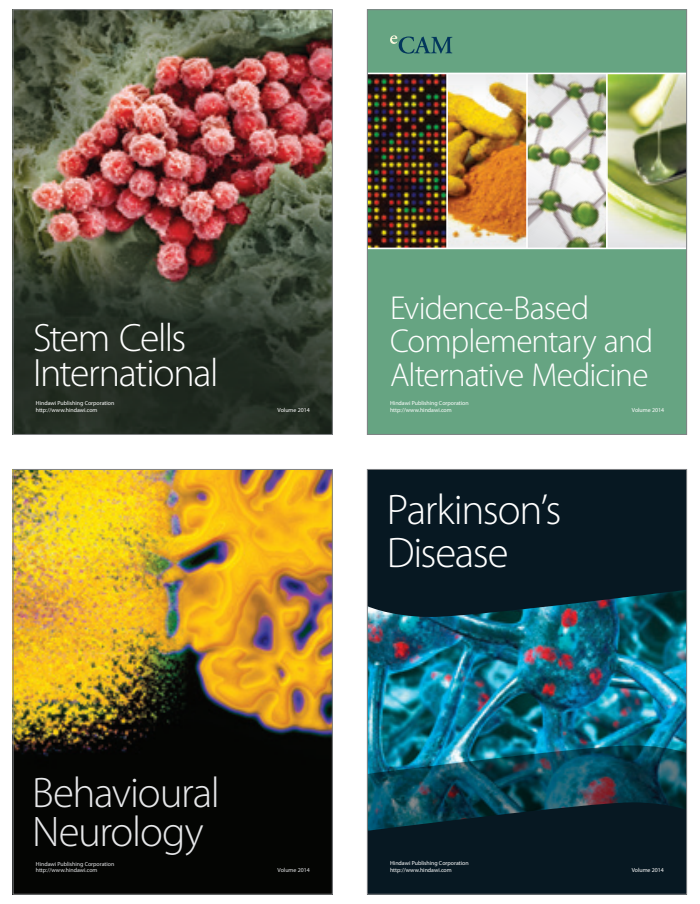
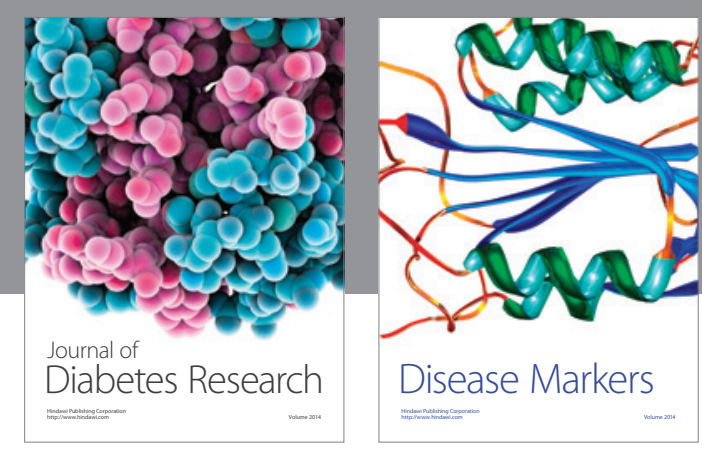

Disease Markers
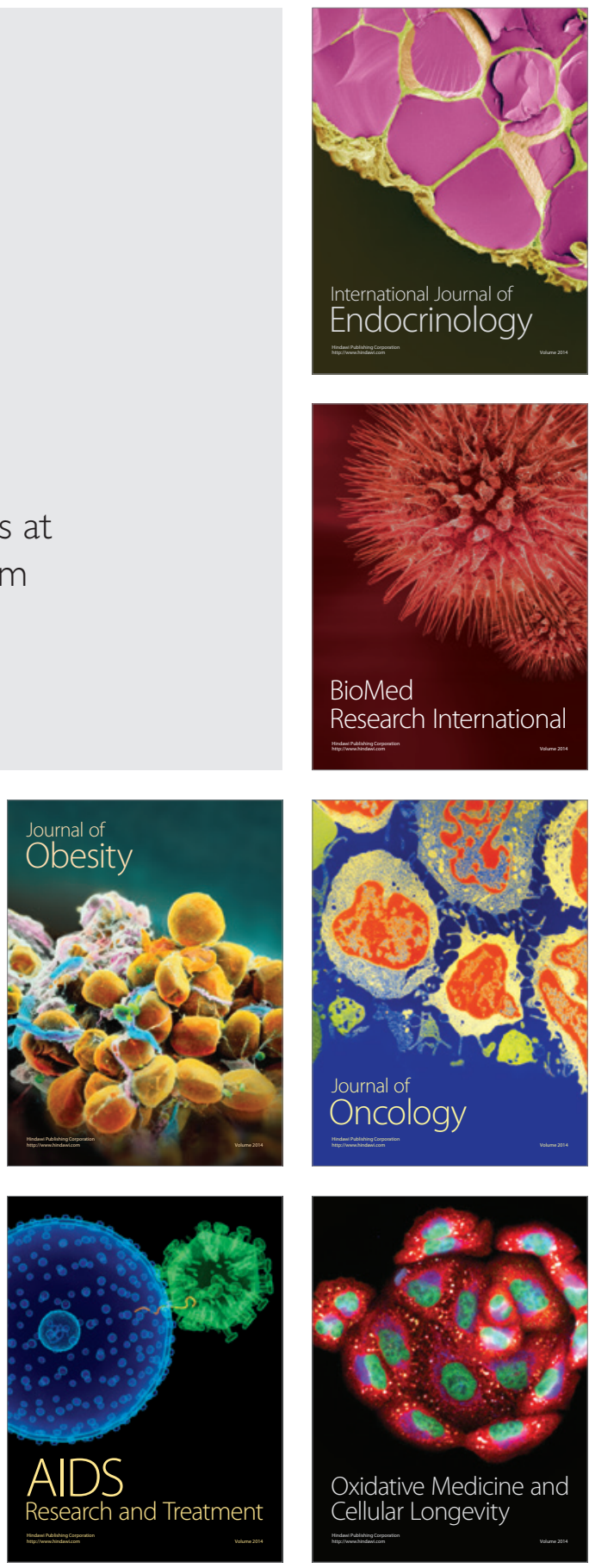